\title{
Tools for monitoring remission in rheumatoid arthritis: any will do, let's just pick one and start measuring
}

\author{
Yusuf Yazici*1 and Ismail Simsek² \\ See related research by Zhang et al., http://arthritis-research.com/content/14/3/R156
}

\begin{abstract}
Rheumatoid arthritis treatment has seen major changes in the last decade, one of which is the concept of treating to target. Various composite outcome measures have been developed, and the latest is the new American College of Rheumatology/European League Against Rheumatism remission criteria. Zhang and colleagues test the predictive validity of the new criteria in an observational cohort and show that they work as well as other definitions of remission. Our main challenge remains getting rheumatologists to use one of the outcome measures rather than developing new measures that are basically no different from already available measures in predicting functional and radiographic changes, the two most important longterm outcomes of rheumatoid arthritis.
\end{abstract}

In a previous issue of Arthritis Research \& Therapy, Zhang and colleagues test the predictive validity of the new American College of Rheumatology (ACR)/European League Against Rheumatism (EULAR) remission criteria in an observational study, the French ESPOIR cohort [1]. Patients with early rheumatoid arthritis (RA) from 14 regions across France have been included in the ESPOIR cohort since 2002, and return to the clinic for follow-up every 6 months during the first 2 years and every year afterwards. For this study, a total of 641 patients fulfilling the 2010 ACR/EULAR classification criteria for RA were included.

Likelihood ratios (LR) are considered to provide a better understanding of how well these candidate

*Correspondence: yusuf.yazici@nyumc.org

'NYU Hospital for Joint Diseases, 333 East 38th Street, New York, NY 10016, USA Full list of author information is available at the end of the article definitions performed. In this regard, the LR for each candidate definition was calculated by comparing the proportion of patients having a good outcome (for both radiographic damage and physical function over the interval of 12 to 24 months after they first reached remission) and whose RA was in remission with the proportion of patients having a good outcome whose RA was not in remission. The Boolean definitions with the highest LRs (2.6) for good outcomes were those that had at least five measures - tender joint count (TJC), swollen joint count (SJC), C-reactive protein (CRP), patient global assessment, and physician global assessment or patient pain - while the ACR/EULAR-recommended four-item remission definition performed very similarly $(L R=2.4)$. With regard to index-based definitions, the ACR/ EULAR-recommended Simplified Disease Activity Index (SDAI) $\leq 3.3$ performed best among the others (28-joint Disease Activity Score (DAS28) $<2.6$ and $<2.0$ ). In terms of definitions for clinical practice, which do not need CRP measurements, the remission definition of the Clinical Disease Activity Index (CDAI) that had four measures (TJC, SJC, patient global assessment, and physician global assessment) performed better $(\mathrm{LR}=2.3)$ compared with those recommended by the ACR/EULAR (28-joint TJC, 28-joint SJC, patient global assessment $\leq 1$ and $\mathrm{CDAI} \leq 2.8$ ) with $\mathrm{LR}=2.0$.

Overall, predictive validity analysis of the dataset obtained from the observational ESPOIR study shows us that the new RA remission definitions perform as comparably in observational studies as in clinical trials, while the LRs for several candidate definitions found in this cohort were a bit lower compared with those found in clinical trial datasets.

The last decade witnessed revolutionary developments in RA treatment with the advent of targeted biologic therapies and the use of a tightly controlled treatment approach, which have fostered improved outcomes [2]. True remission has thus now become a reality for some of our patients. Various composite disease activity indices 
were already in use - the DAS28, SDAI, CDAI and Routine Assessment of Patient Index Data 3 (RAPID3) when the ACR and the EULAR came together with the Outcome Measures in Rheumatology Initiative, and jointly convened a committee in 2007 and reached a consensus on the ACR/EULAR definition of remission for RA in 2011 [3]. The committee proposed two definitions of remission: an index-based score (defining remission as SDAI score $\leq 3.3$ ); and a Boolean-based definition, which was developed using datasets from four clinical trials. However, as also stated in the original report, this needed to be validated in observational cohorts, which is a requirement to recommend their use in clinical practice [3].

Before we decide on which definition/measure to use in routine clinical care, it is important to know how the new ACR/EULAR remission criteria were developed. The ACR has focused on the need for assessing disease activity, with continued monitoring in the last two recommendations it published $[4,5]$. These suggest that the DAS28, SDAI, CDAI and RAPID3 are virtually identical and interchangeable for use in routine clinical care. However, there has been concern for some time now that it was possible to achieve DAS28 remission (score $<2.6$ ) but still have several swollen and tender joints [2]. To develop a more stringent remission definition, the ACR/EULAR committee therefore decided that functional outcome and radiographic damage should be used to validate candidate remission definitions because the chosen new remission definition should predict future good functional outcomes and an absence of radiographic damage progression. They then, as stated in the manuscript, '... by consensus ... agreed that any definition should include, as a minimum, tender and swollen joint counts and levels of an acute phase reactant' [3]. Ten different combinations of the ACR core dataset measures, always including the SJC, TJC and CRP, were then tested in cohorts of patients.

The first issue that arises from this testing is that if this was an exercise in trying to find a better, more stringent definition of remission, why were all possible combinations of the ACR dataset measures not tested? Zhang and colleagues' paper in a previous issue of Arthritis Research $\mathcal{E}$ Therapy suggests that there may have been better definitions to consider. Why is there a need to limit the options only to those combinations that have the SJC, TJC and CRP as part of the definition? Why not let the data speak for themselves?

We think part of the problem is that most physicians believe that physician-driven measures are more objective compared with the so-called subjective patient measures. Yet data suggest that patient-driven measures are actually more accurate in demonstrating what is going on with the patients earlier and are less susceptible to placebo effects $[6,7]$. Hence, asking a patient how they are doing and documenting their response may be more objective and a true reflection of how they are doing compared with asking a physician to perform a joint count and base their decisions on that. In addition, data suggest that, regardless of the definition of remission used - including the Boolean ACR/EULAR definition functional outcomes and radiographic progression are similar in groups of patients $[8,9]$. Our own data show that remission rates as measured by RAPID3, a patientonly composite index, and the Boolean ACR/EULAR definition capture virtually the same patients and that there does not seem to be an advantage to the new definition over what has already been in use [10].

The other, more critical, issue is that if physicians do not use a measure, it really does not matter how good that measure is. Joint examination is of course part of the clinical encounter with a rheumatologist, but actual 28-joint counts or other versions of joint counts are not performed frequently in routine clinical care and CRP is not always available at the time of the visit [11]. Measures that include these components are therefore going to be hard to implement, turning into a road block to 'treat to target', whereas a patient questionnaire as part of the structure of medical care is easy to implement, does not take extra time from the physician and seems to be equivalent to any other measure [12].

In conclusion, we believe that we already have enough measures that work both in clinical trials and in routine clinical care. Why try to add more measures when our efforts need to be focused on educating physicians how to use them and get them started on the road to treating to target? It may be worth remembering Benjamin Franklin when he said 'Lose no time; be always employed in something useful; cut off all unnecessary actions' before the ACR and the EULAR next decide to work on a joint project.

\section{Abbreviations}

ACR, American College of Rheumatology; CDAl, Clinical Disease Activity Index; CRP, C-reactive protein; DAS28, 28-joint Disease Activity Score; EULAR European League Against Rheumatism; LR, likelihood ratio; RA, rheumatoid arthritis; RAPID3, Routine Assessment of Patient Index Data 3; SDAl, Simplified Disease Activity Index; SJC, swollen joint count; TJC, tender joint count.

\section{Competing interests}

IS has received honoraria from Abbott Laboratories and Pfizer, Inc. YY has acted as a consultant for Abbott, BMS, Celgene, Genentech, Horizon, Janssen, Pfizer, and UCB, and has received research support from BMS, Centocor, Genentech, and Celgene.

\section{Author details}

${ }^{1}$ NYU Hospital for Joint Diseases, 333 East 38th Street, New York, NY 10016, USA. ${ }^{2}$ Division of Rheumatology, Gulhane School of Medicine, GATA

Romatoloji BD, 06018, Etlik, Ankara, Turkey.

Published: 28 January 2013

\section{References}

1. Zhang B, Combe B, Rincheval N, Felson DT: Validation of ACR/EULAR definition of remission in rheumatoid arthritis from RA practice: the 
ESPOIR cohort. Arthritis Res Ther 2012, 14:R156.

2. Schoels M, Knevel R, Aletaha D, Bijlsma JW, Breedveld FC, Boumpas DT, Burmester G: Evidence for treating rheumatoid arthritis to target: results of a systematic literature search. Ann Rheum Dis 2010, 69:638-643.

3. Felson DT, Smolen JS, Wells G, Zhang B, van Tuyl LH, Funovits J: American College of Rheumatology/European League Against Rheumatism provisional definition of remission in rheumatoid arthritis for clinical trials. Arthritis Rheum 2011, 63:573-586.

4. Saag KG, Teng GG, Patkar NM, Anuntiyo J, Finney C, Curtis JR, Paulus HE, Mudano A, Pisu M, Elkins-Melton M, Outman R, Allison JJ, Suarez Almazor M, Bridges SL Jr, Chatham WW, Hochberg M, MacLean C, Mikuls T, Moreland LW, O'Dell J, Turkiewicz AM, Furst DE; American College of Rheumatology: American College of Rheumatology 2008 recommendations for the use of nonbiologic and biologic disease-modifying antirheumatic drugs in rheumatoid arthritis. Arthritis Rheum 2008; 59:762-784.

5. Singh JA, Furst DE, Bharat A, Curtis JR, Kavanaugh AF, Kremer JM, Moreland LW, O'Dell J, Winthrop KL, Beukelman T, Bridges SL Jr, Chatham WW, Paulus HE, Suarez-Almazor M, Bombardier C, Dougados M, Khanna D, King CM, Leong AL, Matteson EL, Schousboe JT, Moynihan E, Kolba KS, Jain A, Volkmann ER, Agrawal H, Bae S, Mudano AS, Patkar NM, Saag KG: Update of the 2008 American College of Rheumatology recommendations for the use of disease-modifying antirheumatic drugs and biologic agents in the treatment of rheumatoid arthritis. Arthritis Care Res (Hoboken) 2012; 64:625-639.

6. Strand V, Cohen S, Crawford B, Smolen JS, Scott DL; Leflunomide Investigators Groups. Patient-reported outcomes better discriminate active treatment from placebo in randomized controlled trials in rheumatoid arthritis. Rheumatology (Oxford) 2004, 43:640-647.

7. Yazici Y, Curtis JR, Ince A, Baraf H, Malamet RL, Teng LL, Kavanaugh A: Efficacy of tocilizumab in patients with moderate to severe active rheumatoid arthritis and a previous inadequate response to disease-modifying antirheumatic drugs: the ROSE study. Ann Rheum Dis 2012, 71:198-205.

8. Lillegraven, S, Prince FH, Bykerk VP, Shadick NA, Lu B, Frits ML, lannaccone CK, Haavardsholm EA, Kvien TK, Weinblatt ME, Solomon DH: Radiological progression in remission by the new ACR/EULAR criteria for remission: a comparison to other established remission criteria. Ann Rheum Dis 2011 70(Suppl):S651.

9. Uhlig T, Lie E, Kaufmann C, Rodevand E, Mikkelsen K, Kalstad SK, Tore K: Different remission definitions capture different proportions of patients with rheumatoid arthritis treated in clinical practice. Arthritis Rheum 2011, 63(Suppl):S480

10. Yazici, Y, Filopoulos MT, Swearingen CJ: RAPID3 remission vs new ACR RA remission criteria: RAPID3 has similar utility and may be used in everyday clinical care. Arthritis Rheum 2011, 63(Suppl):S959.

11. Pincus T, Segurado OG: Most visits of most patients with rheumatoid arthritis to most rheumatologists do not include a formal quantitative joint count. Ann Rheum Dis 2006, 65:820-822.

12. Pincus T, Yazici Y, Bergman M, Swearingen C, Harrington T: A proposed approach to recognise 'near-remission' quantitatively without formal joint counts or laboratory tests: a patient self-report questionnaire routine assessment of patient index data (RAPID) score as a guide to a'continuous quality improvement'. Clin Exp Rheumatol 2006, 24(6 Suppl 43):S60-S73.

doi:10.1186/ar4139

Cite this article as: YaziciY Simsek l: Tools for monitoring remission in rheumatoid arthritis: any will do, let's just pick one and start measuring. Arthritis Research \& Therapy 2013, 15:104. 